\title{
TRIBOLOGY CONSIDERATIONS REGARDING THE REPLACEMENT OF THE OLC45 MATERIAL,WITHOUT HEAT TREATMENT, WITH OL52 IN ORDER TO IMPROVE THE PRODUCT CONVEYOR ROLLERSUPPORT PIN
}

\author{
CIPRIAN DAN BÂTIU \\ Faculty of Engineering/Department of Industrial Machinery and Equipment, “Lucian Blaga” University, Sibiu, \\ Romania, ciprian.batiu@ulbsibiu.ro
}

\begin{abstract}
The experimental approach to the galling process of the materials used in machinery industry is a very important point in determining the durability of the contact surfaces of two materials. This paper is an experimental study designed to analyze the contact surface of a metallic material such as OL52, and also the wear of the material after the application of force. For the study there was used a test stand which has attached a weight, sliding on a certain ruler, an electric motor and a dial indicator which can identify the amperage value. There were used charts, graphics, and also photographic images and corresponding tables.
\end{abstract}

Keywords: tribology, wear, lubricanting, transmission oil

\section{Introduction}

The product used for testing is a conveyor roller support pin, according toISO 2338, having a roughness of $0.8 \mu \mathrm{m}$ as presented in Figure 1.

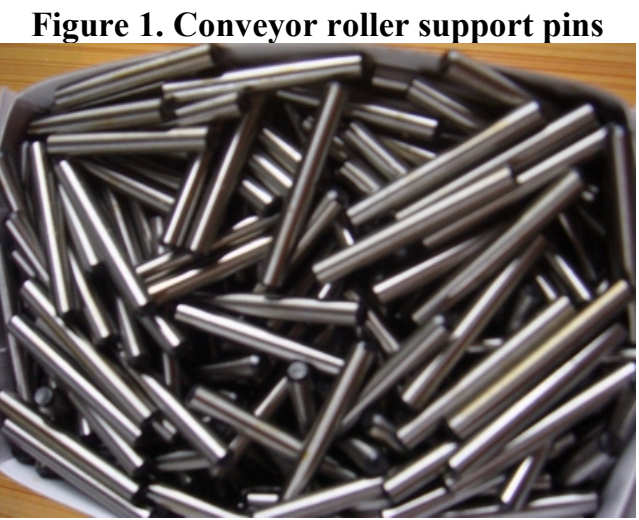

The type of lubricating is oil dripping. In this experiment it was used T90 gear oil. The characteristics of such transmission oil are recommended for all automotive and industrial gear units to meet the technical requirements of operation. It is known that T90 gear oil has high anti-wear properties, and oxidation resistance. However it maintains its optimal working conditions for a long period of time. Characteristic values of T90 oil are presented in Table 1.

Table 1. T90 oil characteristics

\begin{tabular}{|c|l|c|c|}
\hline Nr. Crt. & \multicolumn{1}{|c|}{ Characteristics } & STAS check methods & Parameter' values* \\
\hline $\mathbf{1}$ & Relative density at $20^{\circ} \mathrm{C}, \mathrm{kg} / \mathrm{m}^{3}, \mathrm{max}$. & STAS $35 / 81$ & 0,915 \\
$\mathbf{2}$ & Kinematic viscosity at $100^{\circ} \mathrm{C}, \mathrm{mm}^{2} / \mathrm{c}$ & STAS $117 / 87$ & 16,5 \\
\hline $\mathbf{3}$ & Viscosity index, minimum & STAS 55/81 & 96 \\
$\mathbf{4}$ & Pour point, ${ }^{\circ} \mathrm{C}, \max$ & STAS 39/80 & -20 \\
\hline $\mathbf{5}$ & Flash point in open cup, ${ }^{\circ} \mathrm{C}$ min & STAS 5489/80 & 220 \\
\hline
\end{tabular}


The aim of the experiment is to identify the connection between the two materials, to observe and measure the wear by contact between two materials at different values of force application.

\section{Sections}

The technology of the experiment:

\section{A. The stand}

The stand has a support on which is mounted a ruler. The weight used slides on this ruler, and on the opposite side of the stand is attached to a threaded rod on which is mounted a counterweight so stand to be in total equilibrium.

Also to the support it is attached a lever for making the link with the mechanism of action, where a test piece of material is mounted.

The test piece of material has a diameter of $10 \mathrm{~mm}$ and a length of $10 \mathrm{~mm}$. It is mounted in a device that enables contact between the specimen and the cylinder found in the sump. After auctioning the engine (the engine is constructed by the company MAGNETEK and has an output of $0.25 \mathrm{~kW}$ ), the cylinder is lubricated and the friction between the specimen and the cylinder is a fluid friction. It is worth mentioning that the cylinder found in the oil sump is made of a material for bearings RUL 2.

The input data of this experiment are as follows:

- The force acting on the specimen, calculated as the weight acting on the mechanism;

- The exact lengths between the components of the stand, and between the areas of contact between the specimen and the cylinder;

- The length of travel of the weight on the ruler

\section{Figure 2. The stand}
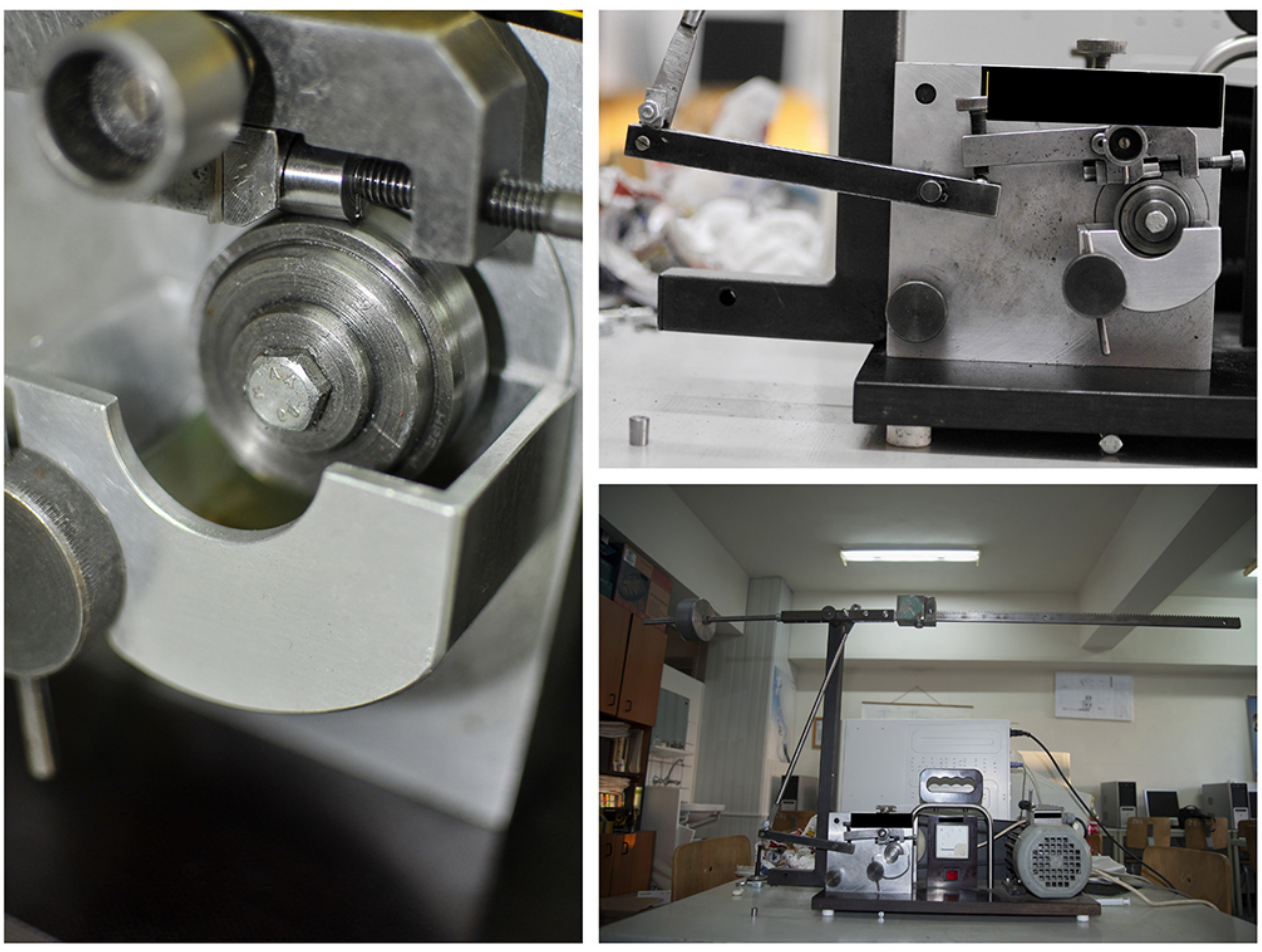

\section{B. Stages of the experiment}

- Equilibrate the system by bringing the weight to the limit 0 (zero) of the ruler and moving the counterweight on the threaded rod so that the system is perfectly horizontal;

- The sample is mounted on the device so as to be in contact with the cylinder;

- The oil tank is fed with T90 gear oil (about $15-20 \mathrm{ml}$ );

- The engine is started via the power button for 30 seconds;

- During the operation it is identified the amount of amperage on the dial indicator;

- The engine is switched off and then it is identified the contact area after the applying the load; 
- There are determined further experimental tests so that the weight to be moved from 10 to 10 $\mathrm{mm}$ on the grid, and each time the specimen is removed from the device so that there can be found another area of contact.

\section{Presentation of the experimental results}

The experiments were conducted on two samples: a specimen of OL52 and a specimen of OLC45. The Brinell hardness for OL52 and for OLC45 is $187 \mathrm{HB}$ and 207HB respectively. Eight experiments were performed for each specimen. The specimens were subjected to a constant force $\mathrm{F}=3.654 \mathrm{~N}$, and for each experiment, the weight which mass is $\mathrm{m}=0.995 \mathrm{~g}$, was moved from 10 to $10 \mathrm{~mm}$.

The results of the experiment are given in Table 2 and for each experiment separately it was determined the footprint of the two materials, the length and the width.

Table 2. Results of the experimental study

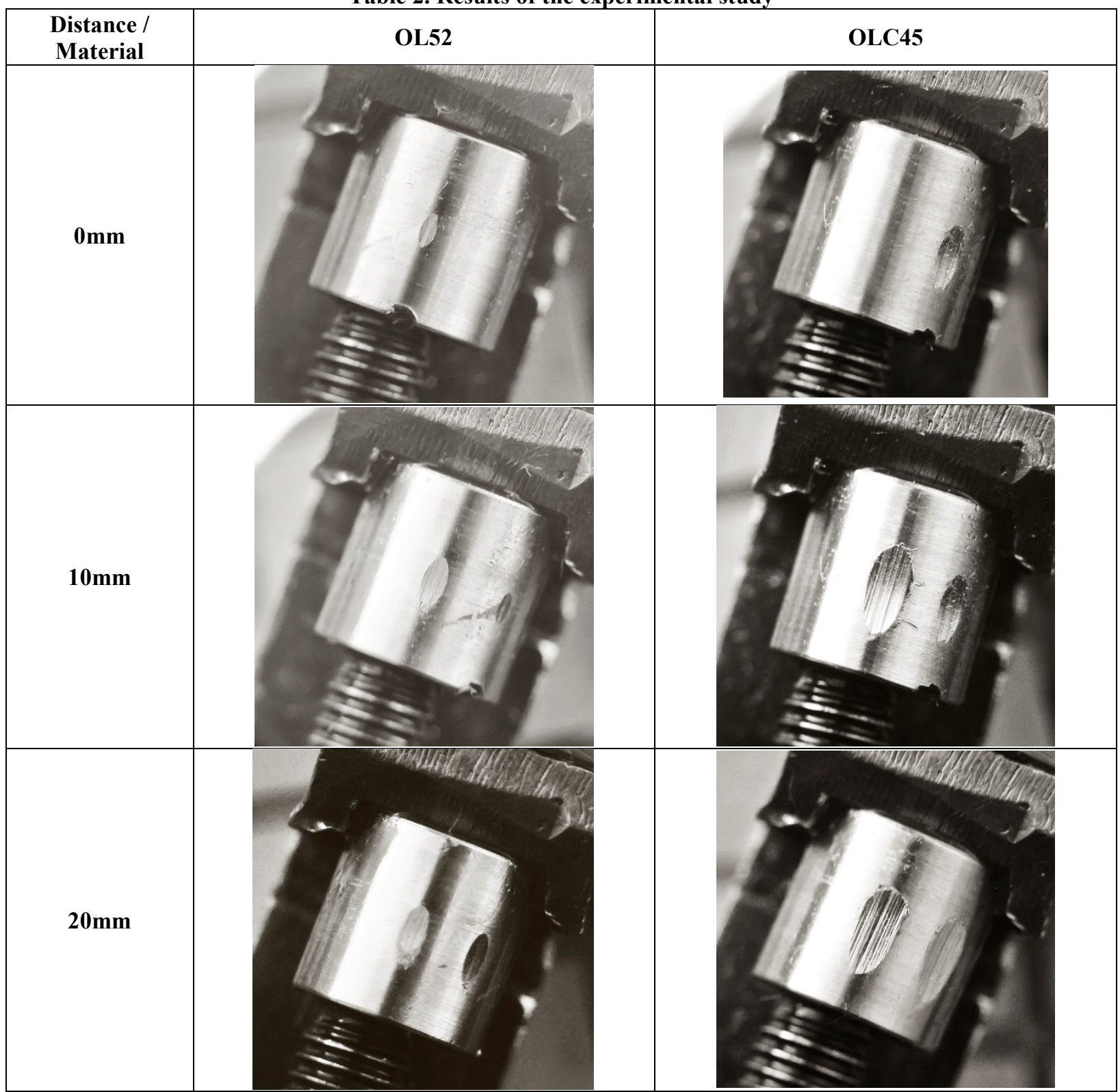




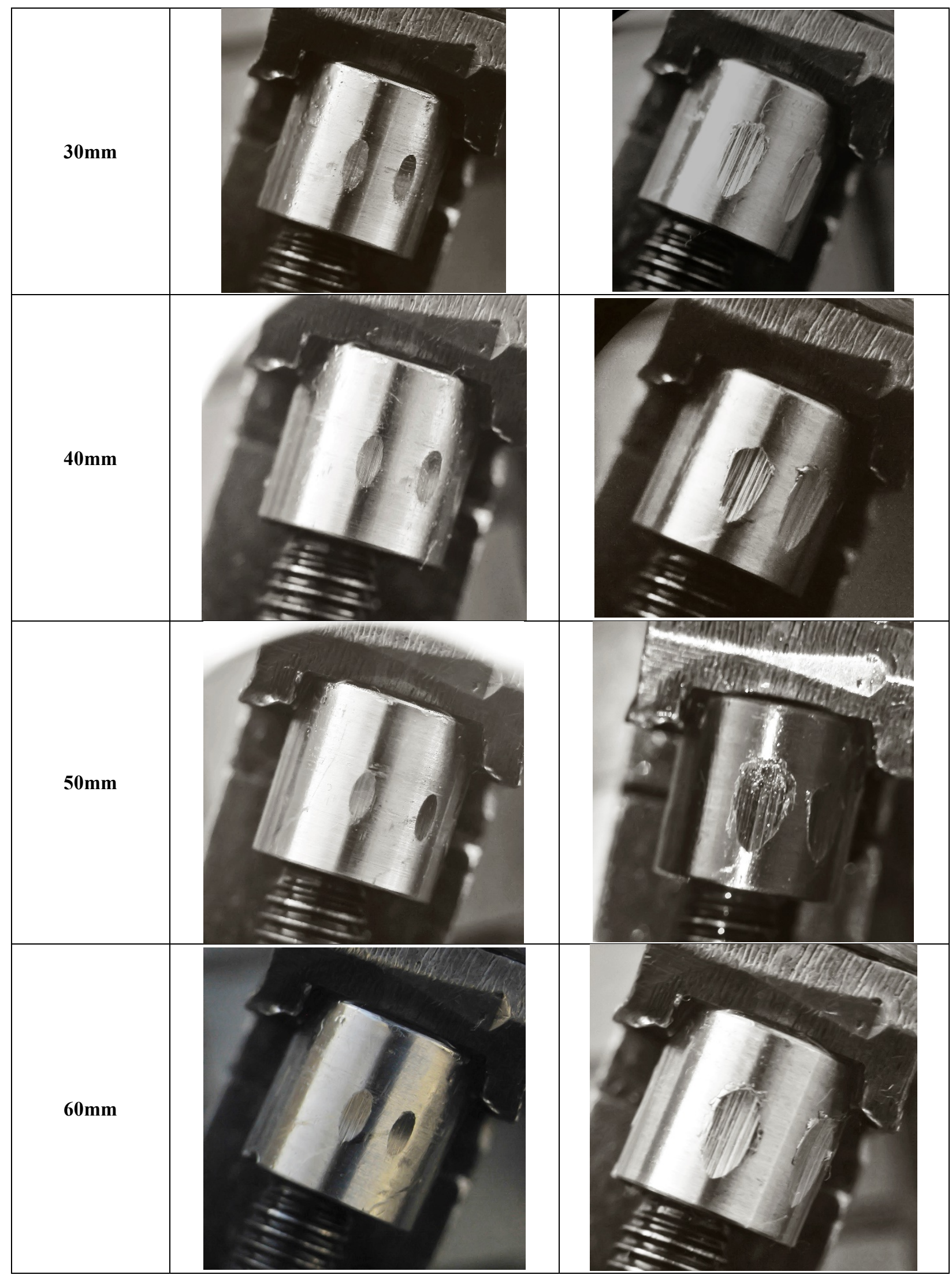




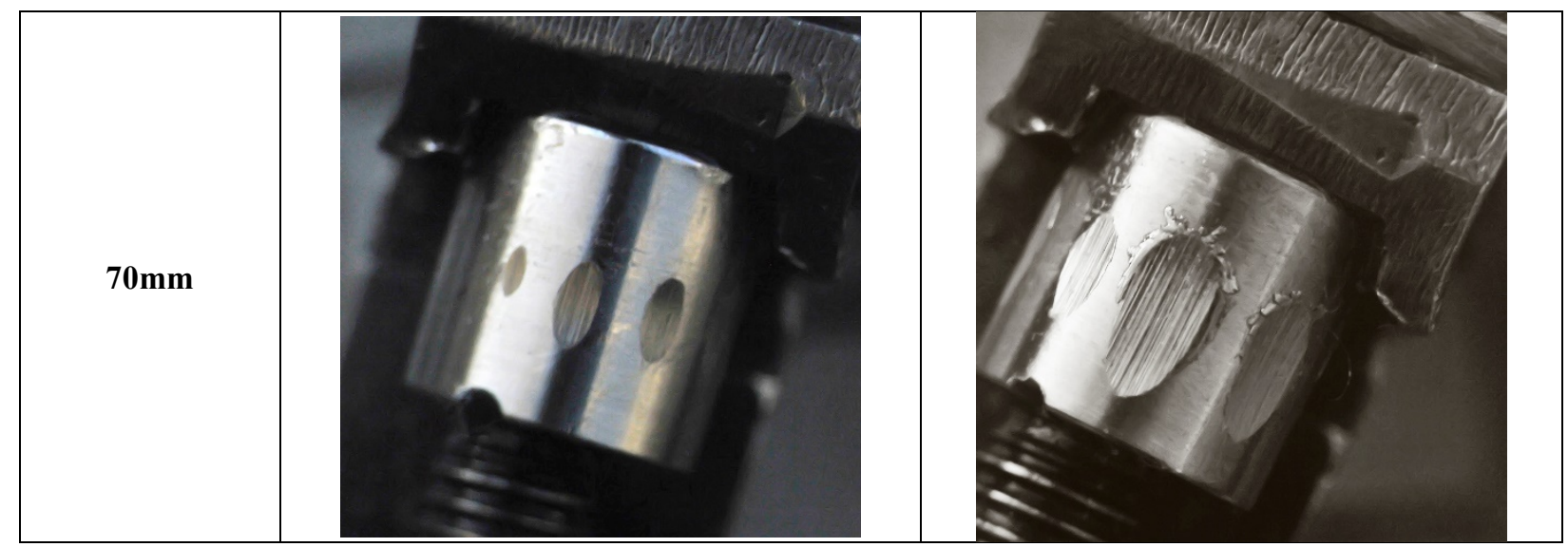

Chart 1 and Chart 2 show a characteristic length, respectively the width of the footprint of the material submitted to experiment.

Chart 1. Length feature of the footprint

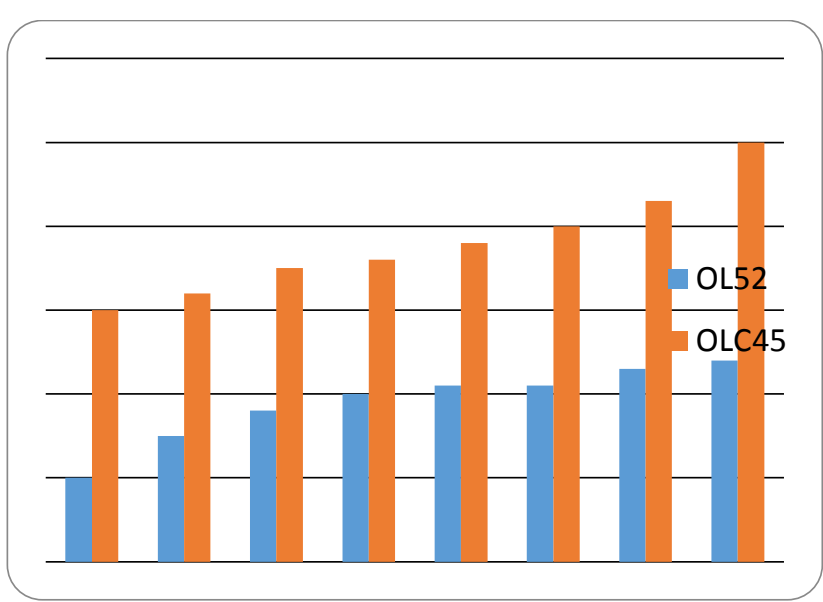

Chart 2. Width feature of the footprint

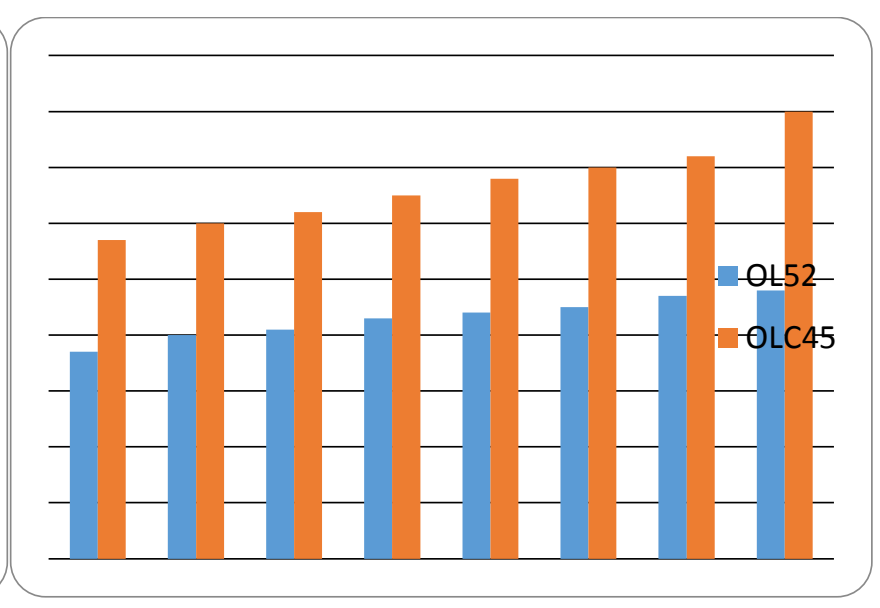

\section{Conclusions}

After all the tests were conducted we observed that despite the fact that the Brinell hardness of OL52 is lower than the one of OLC45, the contact spots (footprints) between the OLC45 samples and the cylinder mounted on the stand are more pronounced than the contact spots on the OL52 samples.

The roughness after the test was performed by visual comparison and the conclusion is that the trail contact spots of the OLC45 samples are much tougher visually and are highlighted through a much higher wear considering that the duration of each experiment is 30 seconds.

OL52 and OLC45 are two soft steels, but because the $0.45 \% \mathrm{C}$ inthe composition of OLC45 have had an influence on the wear, OL52 is recommended for use instead of OLC45.

\section{References}

- Cofaru, N. (2001) Modelarea proceselor de uzare abraziva. Editura "Lucian Blaga" din Sibiu

- Cofaru, N.; Borza, S. (2006) Uzarea abraziva a materialelor compozite utilizate in stomatologie. Annals of the Oradea University. Fascicle of Management and Technological Engineering, p. 1247 $-1253$.

- Serban, R.I. (1997) Tribologie. Privire de ansamblu - Frecarea. Editura "Gheorghe Asachi" Iasi.

- Serban, R.I. (2007) Elemente de inginerie mecanica. Editura "Lucian Blaga" din Sibiu

- http://www.vipoil.ro 